
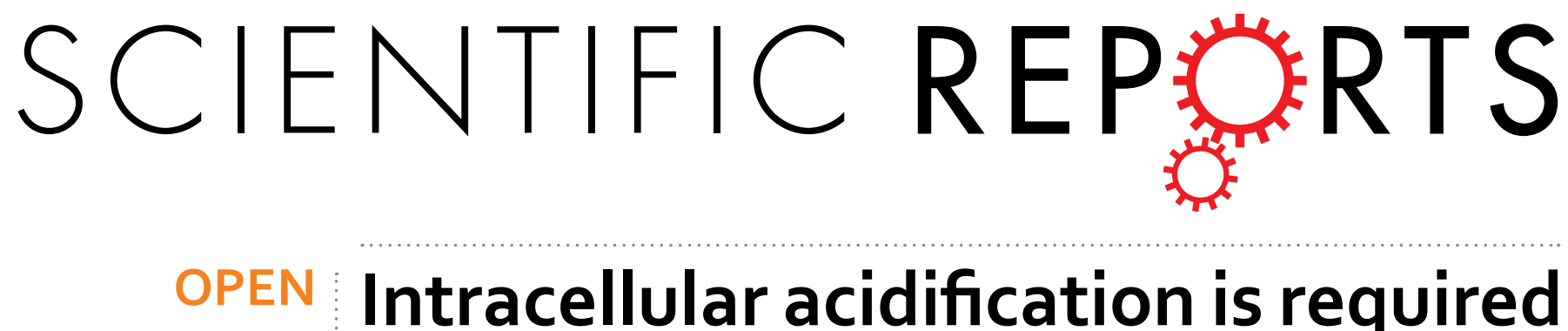

\title{
Intracellular acidification is required for full activation of the sweet taste receptor by miraculin
}

Received: 27 September 2015

Accepted: 19 February 2016

Published: 10 March 2016

\author{
Keisuke Sanematsu ${ }^{1}$, Masayuki Kitagawa ${ }^{1}$, Ryusuke Yoshida ${ }^{1,2}$, Satoru Nirasawa ${ }^{3}$, \\ Noriatsu Shigemura ${ }^{1}$ \& Yuzo Ninomiya ${ }^{1,4}$
}

Acidification of the glycoprotein, miraculin ( $M C L)$, induces sweet taste in humans, but not in mice. The sweet taste induced by MCL is more intense when acidification occurs with weak acids as opposed to strong acids. MCL interacts with the human sweet receptor subunit hTAS1R2, but the mechanisms by which the acidification of MCL activates the sweet taste receptor remain largely unexplored. The work reported here speaks directly to this activation by utilizing a sweet receptorTAS1R2 + TAS1R3 assay. In accordance with previous data, MCL-applied cells displayed a pH dependence with citric acid (weak acid) being right shifted to that with hydrochloric acid (strong acid). When histidine residues in both the intracellular and extracellular region of hTAS1R2 were exchanged for alanine, taste-modifying effect of $M C L$ was reduced or abolished. Stronger intracellular acidification of HEK293 cells was induced by citric acid than by $\mathrm{HCl}$ and taste-modifying effect of $\mathrm{MCL}$ was proportional to intracellular $\mathrm{pH}$ regardless of types of acids. These results suggest that intracellular acidity is required for full activation of the sweet taste receptor by $\mathrm{MCL}$.

One of the most puzzling and striking phenomena in human taste perception is the induction of a strong sweet taste by a sour acid when the sour acid is preceded by tasting a plant-based glycoprotein (itself having no taste) called miraculin (MCL) ${ }^{1,2}$. This 191 amino acid glycoprotein forms a homodimeric complex. Taste-modifying effect of MCL is specific to humans but not to rodents ${ }^{2-5}$.

Sweet taste is mediated by the heterodimer receptor of taste type 1 receptor proteins, TAS1R2 and TAS1R3, expressed in subsets of taste receptor cells $s^{6,7}$. The TAS1Rs belong to the class C G-protein-coupled receptor (GPCR) family, and consist of three principal domains: an amino-terminal domain (ATD) and a cysteine-rich domain (CRD) located in the extracellular region, and a transmembrane domain (TMD) ${ }^{8}$. A previous study suggested that amino acid residues 448 to 494 in the ATD of hTAS1R2 are required for sweet taste induction by $\mathrm{MCL}^{9}$. Replacement of histidine residues in MCL with alanine leads to the loss of this effect suggesting that acidification induces a necessary conformational change in $\mathrm{MCL}^{10}$.

Psychophysical studies have shown that the type of acid affects the strength of the taste modifying effect of MCL: Weak acids produce a more potent taste-modifying effect than do strong acids ${ }^{2}$. This difference is also observed in sour taste alone as sour sensation is more intense with weak acids than strong acids ${ }^{2}$. Here we provide a molecular explanation for this remarkable phenomenon and argue that it provides new insights into the fundamental mechanisms underlying sour taste perception.

\section{Results}

Taste-modifying effect of MCL requires the ATD of hTAS1R2. We examined the effect of solution properties (e.g., $\mathrm{pH}$ ) on the interaction of MCL with the sweet taste receptor using transient transfection of HEK293 cells by the sweet taste receptor, TAS1R2 + TAS1R3, along with Go16-gust44. Receptor activity was monitored by calcium responses. We found that these cells were sensitive to various sweet compounds, but not to citric acid ( $\mathrm{pH} 5.0)$. Upon application of $\mathrm{MCL}(10 \mu \mathrm{g} / \mathrm{ml})$ alone at neutral $\mathrm{pH}$, the transfected cells showed no 
hTAS1R2 + hTAS1R3

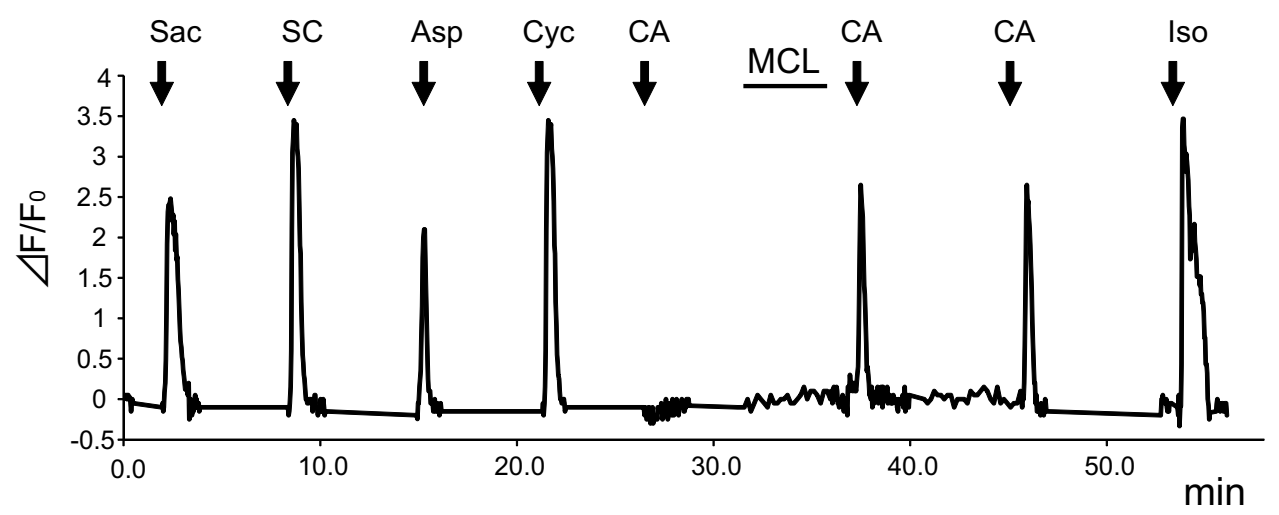

Figure 1. The taste-modifying compound miraculin (MCL) induces its effect via the human sweet taste receptor. Typical example of single cell $\mathrm{Ca}^{2+}$ imaging is shown. HEK293 cells heterologously expressing hTAS1R2 + hTAS1R3 showed calcium responses to non-nutritive sweeteners $10 \mathrm{mM}$ saccharin (Sac), $0.3 \mathrm{mM}$ SC45647 (SC), $10 \mathrm{mM}$ aspartame (Asp) and $30 \mathrm{mM}$ cyclamate (Cyc), but not to $3 \mathrm{mM}$ citric acid (CA: $\mathrm{pH}$ 5.0). After application of MCL $(10 \mu \mathrm{g} / \mathrm{ml})$, this cell showed responses to citric acid. Control: $10 \mu \mathrm{M}$ isoproterenol (Iso).

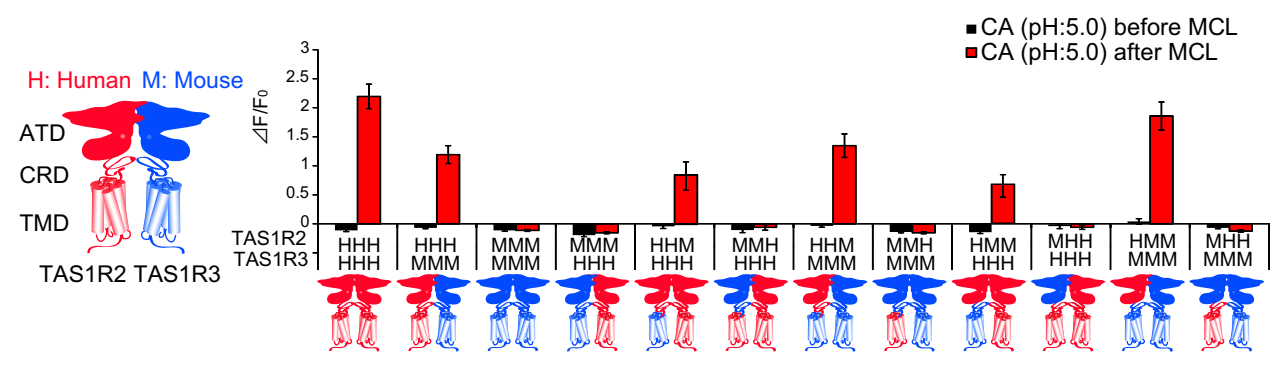

Figure 2. The amino-terminal domain (ATD) of hTAS1R2 is required for sensitivity to MCL. HEK293 cells were transiently transfected with full length and/or chimera of TAS1R2 and TAS1R3, and Ga16-gust44. TAS1R2 (left) and TAS1R3 (right) are shown by schematic receptors. ATD, amino-terminal domain; CRD, cysteine-rich domain; TMD, transmembrane domain. The full length and the chimera of TAS1Rs are indicated by three letters including of $H$ (human; red) or $M$ (mouse; blue) (example, chimera containing the ATD and the CRD of human receptor coupled to the TMD of mouse receptor as for HHM). The responses of the receptors to $3 \mathrm{mM}$ citric acid (CA: $\mathrm{pH} 5.0)$ before and after application of MCL $(10 \mu \mathrm{g} / \mathrm{ml})$ were examined. 15-30 cells. Data are expressed as means \pm S.E.

calcium response. However, when citric acid was subsequently added, a calcium response was observed consistent with the sweet-inducing effect of MCL (Fig. 1). This effect was not observed in HEK293 cells expressing mouse mTas1r2 + mTas1r3 (Fig. 2). These results are also consistent with the species-specific effect of MCL as previously shown by psychophysical and electrophysiological studies ${ }^{2-5}$.

To identify portions of hTAS1R2 and hT1ASR3 required for the sensitivity to MCL, we examined responses of combinations of full length or chimera receptors in human and/or mouse. First, we confirmed that these receptors were functional, except for a heterodimer mTas1r2 + hTAS1R3 as described previously (Supplementary Fig. S1) ${ }^{11}$. These receptors showed responses to artificial sweeteners SC45647 and saccharin. Heterodimers containing the ATD of hTAS1R2 and the TMD of hTAS1R3 showed sensitivity to artificial sweeteners aspartame and cyclamate, consistent with previous studies on binding sites ${ }^{12-14}$ (Supplementary Fig. S1). Second, responses to citric acid ( $\mathrm{pH}$ 5.0) after application of MCL did not depend on whether TAS1R3 originated from mouse or human (Fig. 2). The heterodimer hTAS1R2 + mTas1r3 responded to MCL, showing the species specificity of TAS1R2 but not TAS1R3. Third, the human ATD of TAS1R2 was necessary for the response since heterodimers containing TAS1R2HHM (chimera containing ATD and CRD of human receptor coupled to the TMD of mouse receptor as for HHM) and HMM but not MMH and MHH chimeras showed responses (Fig. 2). From these results, we conclude that the ATD of hTAS1R2 is required for the sweet-inducing effect of MCL.

Intracellular acidification enhances taste-modifying effect of MCL. Previous studies showed that replacement of histidine residues to alanine in MCL and another taste modifier neoculin reduced their taste-modifying effects, suggesting that protonation of histidine residues in MCL and neoculin is important for the acid-induced sweetness ${ }^{10,15,16}$. Protonation of histidine residues would also occur in the sweet taste receptor. 
a

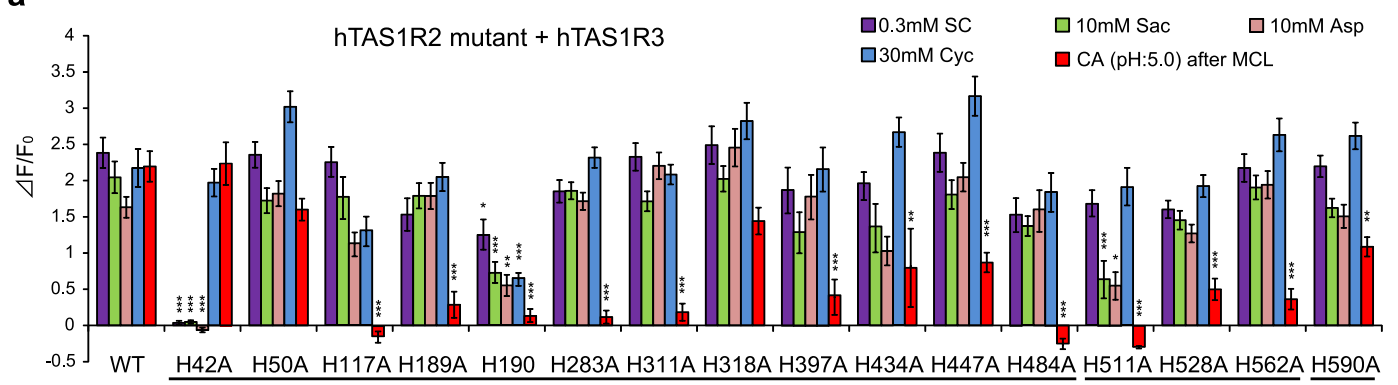

ATD

CRD

TMD

b

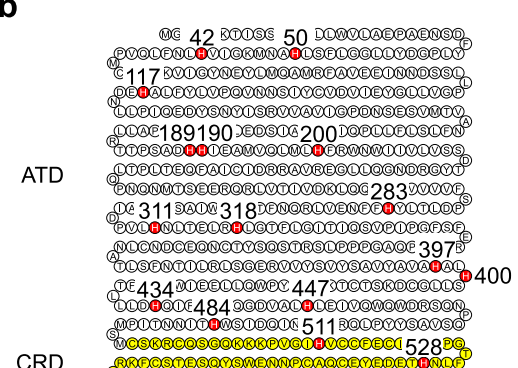

CRD

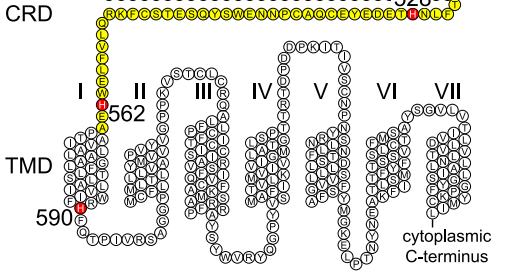

hTAS1R2
C

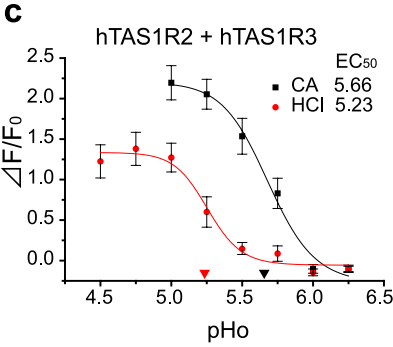

e

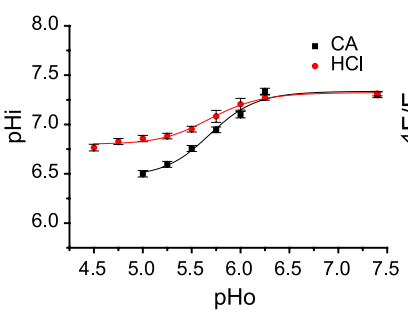

d

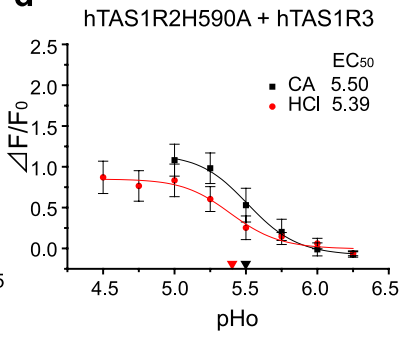

f

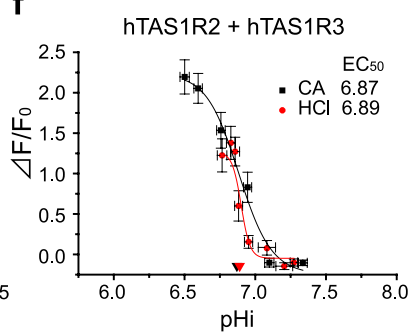

Figure 3. Histidine residues in hTAS1R2 are required for taste-modifying effect of MCL. (a) HEK293 cells were transiently transfected with hTAS1R2 (WT or mutant), hTAS1R3, and Go16-gust44. The responses of the receptors to $0.3 \mathrm{mM} \mathrm{SC} 45647$ (SC), $10 \mathrm{mM}$ saccharin (Sac), $10 \mathrm{mM}$ aspartame (Asp), $30 \mathrm{mM}$ cyclamate (Cyc) and $3 \mathrm{mM}$ citric acid (CA: $\mathrm{pH} 5.0)$ after application of MCL $(10 \mu \mathrm{g} / \mathrm{ml})$ were examined. 15-30 cells. Responses to test solutions were analyzed by multivariate ANOVA followed by Tukey-Kramer test. ${ }^{\star} P<0.05,{ }^{\star \star} P<0.01$, ${ }^{* * *} P<0.001$ vs. $W T$. (b) A snake plot of hTAS1R2. Histidine residues in hTAS1R2 are indicated in red. ATD, Amino-terminal domain; CRD, cysteine-rich domain (shown in yellow); TMD, transmembrane domain. (c) HEK293 cells were transiently transfected with hTAS1R2, hTAS1R3, and Go16-gust44. The extracellular $\mathrm{pH}(\mathrm{pHo}$ ) dependent responses of the receptors to $3 \mathrm{mM}$ citric acid (CA) and $7 \mathrm{mM} \mathrm{HCl}$ after application of MCL $(10 \mu \mathrm{g} / \mathrm{ml})$ were examined. 18 cells. (d) HEK293 cells were transiently transfected with hTAS1R2H590A, hTAS1R3 and Go16-gust44. The pHo-dependent responses of the receptors to $3 \mathrm{mM} \mathrm{CA}$ and $7 \mathrm{mM} \mathrm{HCl}$ after application of MCL $(10 \mu \mathrm{g} / \mathrm{ml})$ were examined. 15-19 cells. (e) Intracellular $\mathrm{pH}$ (pHi) of HEK293 cells was measured after application of different $\mathrm{pH}$ (pHo) of $3 \mathrm{mM} \mathrm{CA}$ and $7 \mathrm{mM} \mathrm{HCl}$. 145-148 cells. (f) Intracellular $\mathrm{pH}$ response curves were obtained by using the same solutions of $3 \mathrm{mM}$ citric acid and $7 \mathrm{mM} \mathrm{HCl}$ in (c). 18 cells. Values are means \pm S.E.

Therefore, we focused on the histidine residues of hTAS1R2 because protonation of these histidine residues may also affect the receptor binding and activity of MCL. We looked at the effect of alanine replacement in hTAS1R2 on responses to several sweeteners as well as $3 \mathrm{mM}$ citric acid after application of MCL (Fig. 3a,b). These responses were significantly different among different mutants (Supplementary Table S1). We found that hTAS1R2H42A showed no response to SC45647, saccharin and aspartame and that hTAS1R2H190A and H511A showed smaller responses to various sweet compounds than wild-type (WT) (post-hoc Tukey-Kramer test, Ps $<0.05$ vs. WT, SC45647, saccharin, aspartame, and cyclamate for H190A; saccharin, and aspartame for H511A) (Fig. 3a). Responses to various sweet compounds in other mutants were not significantly different from those in WT (post-hoc Tukey-Kramer test, Ps $>0.05$ vs. WT). Concerning the effect of MCL, alanine replacements of His-117, 189, 190, 283, 311, 397, and 484 in the ATD, and His-511, 528, and 562 in the CRD of hTAS1R2 abolished or greatly reduced the receptor's sensitivity to citric acid after MCL to below 30\% of WT (post-hoc Tukey-Kramer test, Ps $<0.001$ vs. WT). Mutations of His- 434 and 447 in the ATD and His-590 in the TMD moderately reduced the sweet-inducing effect of MCL to 30-70\% of WT (post-hoc Tukey-Kramer test, Ps $<0.01$ vs. $\mathrm{WT}$ ). These results indicate that mutating histidine for alanine in the ATD of TAS1R2 yields a receptor unable to respond to citric acid after application of MCL.

The effect of MCL is known to differ among different classes of acids in psychophysical and electrophysiological studies in humans and rhesus monkeys ${ }^{2,3}$. This was tested in our expression system using citric acid 
(a weak acid) and $\mathrm{HCl}$ (a strong acid) (Fig. 3c). We found significant differences in responses to citric acid and $\mathrm{HCl}$ after MCL (Fig. 3c and Supplementary Table S2), indicating that weak acids are more potent than strong acids at inducing the taste-modifying effect of MCL.

In mammals the sensation of sourness correlates with titratable acidity better than it does with $\mathrm{pH}^{17}$. Indeed, many studies have reported that intracellular $\mathrm{pH}$ is key to the sensation of "sourness"18-21. For instance, at the same $\mathrm{pH}$, citric acid induces greater decrease in intracellular $\mathrm{pH}$ than $\mathrm{HCl}$ by penetrating plasma membrane as undissociated molecules ${ }^{18}$ and is a more intense sour stimulus than $\mathrm{HCl}^{18-21}$. The taste-modifying effect of MCL by acids exhibits similar properties ${ }^{2}$. Therefore, variations in intracellular acidification may underlie this difference and we tested whether mutation of histidine residues in the intracellular region of hTAS1R2 (hTAS1R2H590A) affects the modifying ability of MCL (Fig. 3b,d). As expected, the difference in response to citric acid and $\mathrm{HCl}$ after MCL was abolished in this mutant (Supplementary Table S2), although responses themselves became smaller compared to those of WT (Supplementary Table S3). Responses to various sweet compounds were not significantly different between this mutant and WT (Fig. 3a), suggesting that this mutation probably does not affect the receptor activation system.

In addition, we monitored intracellular $\mathrm{pH}(\mathrm{pHi})$ in HEK293 cells stimulated with weak and strong acids at different extracellular $\mathrm{pH}$ (pHo) (Fig. 3e and Supplementary Table S4) and examined the relationship between sweet-inducing effect of MCL and pHi (Fig. 3f). Undissociated acids, mainly weak acids, can enter into the intracellular region through the cell membrane, inducing acidification intracellularly. Heightened intracellular acidification was induced by citric acid compared with $\mathrm{HCl}$ (Fig. 3e and Supplementary Table S4). At the same pHi, the calcium responses to citric acid and $\mathrm{HCl}$ after MCL were essentially the same (Fig. 3f). The pHi-dependent curve of citric acid was close to that of $\mathrm{HCl}$ (Fig. 3f), indicating that sweet-inducing effect of MCL is mainly proportional to $\mathrm{pHi}$.

Bathing cells in buffer containing $\mathrm{NaHCO}_{3}$ and sodium acetate at neutral $\mathrm{pH}$ induces intracellular acidification without changing extracellular $\mathrm{pH}^{22}$. We also tested whether such procedures inducing selective intracellular acidification (pHi: $\sim 6.8$ and pHo: 7.2) fully activate the miraculin-bound receptor. After application of MCL, HEK293 cells exhibited no response to these solutions (Supplementary Fig. S2), indicating that both extracellular and intracellular acidification are required for full activation of the sweet taste receptor by MCL.

\section{Discussion}

MCL induces taste-modifying effects in humans, chimpanzees and rhesus monkeys but not in rodents $\mathrm{s}^{2,4,5,23}$. In accordance with those psychophysical and electrophysiological studies, MCL interacted with the human, but not mouse sweet receptor in our sweet receptor assay (Fig. 2), indicating the species-specific effect of MCL. A previous study suggested that the interaction site for MCL is the ATD of hTAS1R2 and the 448 to 494 amino acid residues in hTAS1R2 are required for the effect ${ }^{9}$. We also demonstrated that the ATD of hTAS1R2 is required for sweet-inducing effect of MCL (Fig. 2).

Mutation of His-42 to alanine in hTAS1R2 abolished sensitivity to aspartame, saccharin, and SC45647 but not to cyclamate (Fig. 3a). His- 42 is located in the entrance of the orthosteric binding site for aspartame and saccharin in the ATD of hTAS1R2 ${ }^{13}$. Indeed, Ser-40, close to His-42, is known to be one of the critical residues for the species-dependent difference in sensitivity to aspartame ${ }^{24}$. Our results suggest that replacement of His- 42 with alanine affects conformation of the binding site for aspartame, saccharin, and SC45647 in hTAS1R2 but not the binding site for MCL in hTAS1R2 and cyclamate in hTAS1R3. Thus receptor activation through the interaction between hTAS1R2 and MCL may not require an activation system used by low-molecular weight sweet compounds (aspartame, saccharin, and SC45647) in the ATD of hTAS1R2.

Following replacement of histidine residues to alanine in the extracellular region of hTAS1R2, the taste-modifying effect of MCL was abolished (hTAS1R2-H117A, H484A, H511A) or reduced (hTAS1R2-H189A, H190A, H283A, H311A, H397A, H434A, H447A, H528, and H562A) (Fig. 3a). In some mutants (hTAS1R2H190A and H511A), responses to sweet compounds were significantly reduced (Fig. 3a), suggesting that these mutants have a severe impairment of their receptor activation system. In the other mutants with abolished or reduced MCL effects, mutations may not disturb the receptor activation system since responses to several sweet compounds were not significantly affected (Fig. 3a). We speculate that the binding affinity of MCL to the sweet receptor may not be altered in mutations reducing of the effect of MCL, because the sweet-inducing effect of MCL lasted at least $10 \mathrm{~min}$ despite the continuous washing out of the cell surface. We hypothesize that these mutations may abolish or reduce proton-induced interaction between the sweet receptor and MCL, which leads to activation of the sweet receptor. Also it is possible that binding affinity of MCL to the sweet receptor may be affected by these mutations in TAS1R2. These possibilities should be tested in future studies.

The effectiveness of MCL is known to differ among acids. In humans, the order of the effectiveness of MCL to induce the sweetness by each of acids is as follows: acetic acid (pKa: 4.76), formic acid (pKa: 3.75), lactic acid (pKa: 3.86), oxalic acid (pKa: 1.27) and $\mathrm{HCl}(\mathrm{pKa}:-8.0)^{2}$. In our assay citric acid (weak acid) also induced stronger response than $\mathrm{HCl}$ (strong acid) at the same $\mathrm{pH}$ (Fig. 3c). Weak acid produces more undissociated form of acid than strong acid. Undissociated form of acid could enter into the intracellular region through the cell membrane, which induces acidification intracellularly. Thus weak acids are able to induce intracellular acidification more strongly than strong acids and we demonstrated this using HEK cells (Fig. 3c). Intracellular pH was more closely associated with MCL activity than extracellular $\mathrm{pH}$ (Fig. 3c,f). These results strongly suggest that intracellular acidification could affect the taste-modifying effect of MCL.

Based on our results, we propose a model underlying the taste-modifying effect of MCL (Fig. 4). MCL binds with the ATD of hTAS1R2 as an inactive form at neutral pH. After sufficient extracellular acidification, the extracellular region of hTAS1R2 and MCL are protonated, leading to activation of an intracellular signalling cascades. When a weak acid is applied, undissociated acids cross the membrane of the taste receptor cell, protonating the interior to a level dependent upon the strength of acid. This intracellular acidification leads to a protonation of 


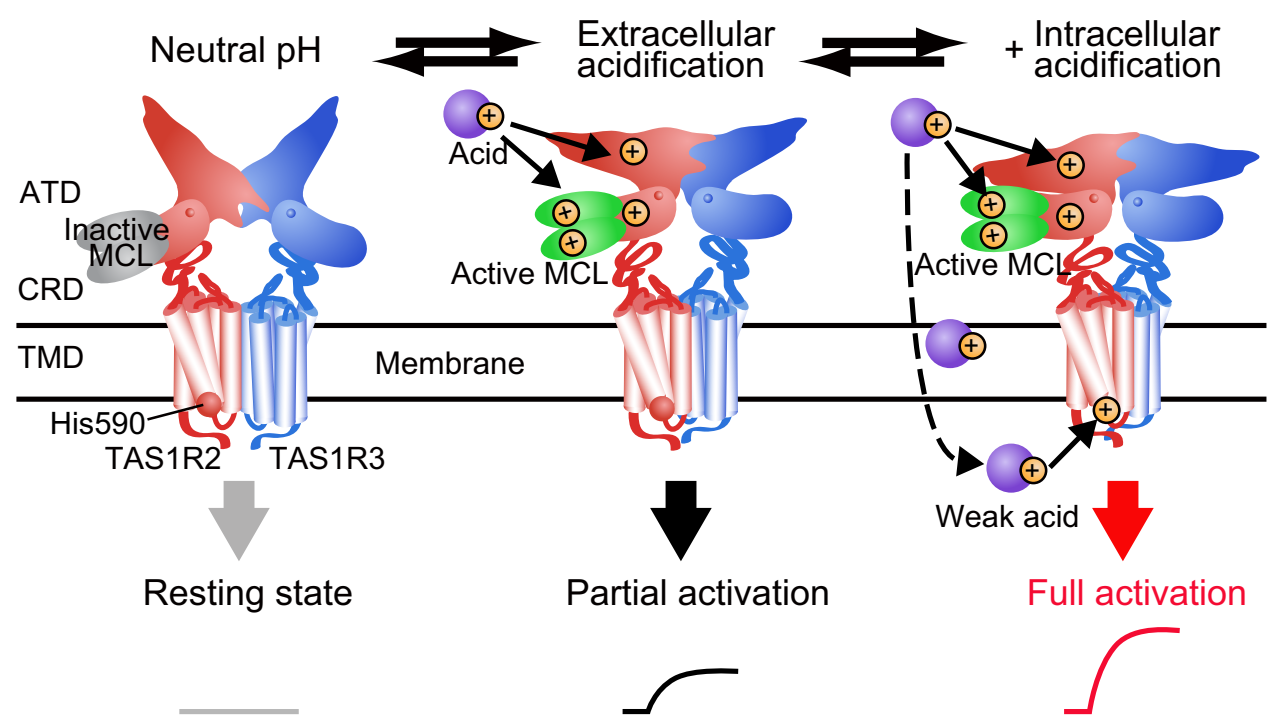

Figure 4. Proposed model for the taste-modifying effect of MCL. MCL (inactive form) binds with the aminoterminal domain of hTAS1R2 at neutral $\mathrm{pH}$, which does not induce activation (left). Extracellular acidification induces partial activation of sweet receptor through the interaction between extracellularly protonated hTAS1R2 and active form of MCL (center). In addition, weak acid enters into intracellular region through cell membrane and causes intracellular acidification leading to full activation.

the intracellular domain of hTAS1R2. Then, full receptor activation is evoked by the interaction between the fully protonated hTAS1R2 and active MCL.

\section{Methods}

All experimental procedures were performed in accordance with the National Institutes of Health Guide for the Care and Use of Laboratory Animals and approved by the committee for Laboratory Animal Care and Use at Kyushu University, Japan.

Preparation of chimeras and point mutations. Human TAS1Rs and Gol6-gust44 expression constructs were generated in the pEF-DEST51 Gateway vector (Life Technologies Corporation) ${ }^{11,25}$. Mouse Tas1r2 and Tas1r3 were cloned as described ${ }^{26,27}$. Construction of human/mouse chimeras of TAS1Rs was performed by PCR using overlapping primers ${ }^{28}$. Point mutations in TAS1R clones were made by site-directed mutagenesis (TAKARA). To subclone each gene into the vector, a Kozak cassette was introduced at the $5^{\prime}$ end before the start codon. The integrity of all DNA constructs was confirmed by DNA sequencing. There are 18 histidine residues in hTAS1R2. Sixteen mutants replacing histidine in hTAS1R2 with alanine were created and their functions were examined. One mutant (hTAS1R2H400A) could not be obtained and the other one (hTAS1R2H200A) did not make a functional receptor.

Functional expression. As described previously ${ }^{11}$, HEK293 cells were kindly provided by Dr. Makoto Tominaga (Okazaki Institute for Integrative Bioscience). These cells were cultured at $37^{\circ} \mathrm{C}$ under a humidified atmosphere containing $5 \% \mathrm{CO}_{2}$ in Dulbecco's modified Eagle's medium supplemented with $10 \%$ fetal bovine serum. To obtain reproducible $\mathrm{Ca}^{2+}$ responses, cells were split every 2 days before the cells became confluent. Cells were discarded after 2 months of passages and new cells were prepared from frozen-stock. For calcium imaging experiments, cells were seeded onto a $35 \mathrm{~mm}$ recording chamber. After $24 \mathrm{hrs}$ at $37^{\circ} \mathrm{C}$, confluent cells (60-70\%) were washed in OptiMEM medium supplemented with GlutaMAX-I (Life Technologies Corporation) and plasmid DNAs were transiently cotransfected into HEK293 cells using Lipofectamine2000 regent (Life Technologies Corporation) $(2.0 \mu \mathrm{l}$ per $1.0 \mu \mathrm{g}$ DNA). TAS1Rs (or their mutants) and Go16-gust44 were transfected using $0.3 \mu \mathrm{g}$ of plasmids for $35 \mathrm{~mm}$ recording chambers. $\mathrm{Ca}^{2+}$ imaging assays were performed $24 \mathrm{hrs}$ after transfection.

Single cell $\mathrm{Ca}^{2+}$ imaging. As described previously ${ }^{11}$, a bath perfusion system was used for determination of the kinetics of activation. Transfected cells in $35 \mathrm{~mm}$ recording chambers were washed in Hank's balanced salt solution (HBSS) (Life Technologies Corporation) containing $10 \mathrm{mM}$ HEPES (pH 7.4), and loaded with $3.0 \mathrm{mM}$ Fluo-4 acetoxymethyl ester (Life Technologies Corporation) for $30 \mathrm{~min}$ at $37^{\circ} \mathrm{C}$. The dye-loaded cells were subjected to $\mathrm{Ca}^{2+}$ imaging. Taste solutions diluted in HBSS containing $10 \mathrm{mM}$ HEPES were applied sequentially to the cells for $30 \mathrm{~s}$ with a peristaltic pump at a flow rate of $1.5 \mathrm{ml} / \mathrm{min}$, and fluorescence images were obtained using a S Fluor 620/0.75 objective lens (Nikon) via a cooled-CCD camera (C6790, Hamamatsu Photonics) fitted to a TE300 microscope (Nikon). AquaCosmos software (v. 1.3, Hamamatsu Photonics) was used to acquire and analyze fluorescence images. A 5 min interval was maintained between each tastant application to ensure that the cells were not desensitized as a result of the previous application of taste solutions. Responses were measured from individual responding cells. MCL $(10 \mu \mathrm{g} / \mathrm{ml})$ were applied to the HEK293 cells for $3 \mathrm{~min}$. Isoproterenol (Iso, 
$10 \mu \mathrm{M}$ ) was used as positive control, which stimulates endogenous $\beta$-adrenergic receptors, providing that the Go16-dependent signal transduction cascade was functional.

Solutions. Chemical compounds were disolved in HBSS containing $10 \mathrm{mM}$ HEPES. Chemical compounds used in this study were saccharin $(10 \mathrm{mM})$, SC45647 $(0.3 \mathrm{mM})$, aspartame $(10 \mathrm{mM})$, and sodium cyclamate $(30 \mathrm{mM})$ as sweet taste stimuli and isoproterenol $(10 \mu \mathrm{M})$ as positive control. We used citric acid ( $\left.\mathrm{pK}_{\mathrm{a}}: 3.09\right)$ (concentration $3 \mathrm{mM}$ in HBSS containing $10 \mathrm{mM}$ HEPES, $\mathrm{pH}$ 7.4, 6.25, 6.0, 5.75, 5.5, 5.25, 5.0 adjusted using $\mathrm{NaOH}$ ), and $\mathrm{HCl}(\mathrm{pKa}:-8.0)$ (concentration $7 \mathrm{mM}$ in HBSS containing $10 \mathrm{mM}$ HEPES, pH 7.4, 6.25, 6.0, 5.75, 5.5, 5.25, $5.0,4.75,4.5$ adjusted using $\mathrm{NaOH}$ ), as a weak acid and strong acid, respectively. We did not use weaker acid like acetic acid (pKa: 4.76) than citric acid, because our pilot studies showed that acetic acid frequently induced nonspecific calcium responses in HEK293 cells in the absence of transfected receptor DNAs as reported previously ${ }^{29}$. For the same reason, citric acid was limited in its usable $\mathrm{pH}$ ( $\mathrm{pH} 5.0$ or above). In all the experiments, we confirmed that acid solutions did not produce calcium responses before application of MCL by means of single cell $\mathrm{Ca}^{2+}$ imaging. For the experiment of intracellular acidification with extracellular neutral $\mathrm{pH}$, we used modified HBSS; $90 \mathrm{mM}$ bicarbonate solution (in mM) $1.26 \mathrm{CaCl}_{2}, 0.493 \mathrm{MgCl}_{2}, 0.407 \mathrm{MgSO}_{4} 5.33 \mathrm{KCl} 0.441 \mathrm{KH}_{2} \mathrm{PO}_{4} 90$ $\mathrm{NaHCO}_{3} 48 \mathrm{NaCl} 0.338 \mathrm{Na}_{2} \mathrm{HPO}_{4} 10$ HEPES and $27.5 \mathrm{mM}$ acetate solution (in mM) $1.26 \mathrm{CaCl}_{2}, 0.493 \mathrm{MgCl}_{2}$, $0.407 \mathrm{MgSO}_{4} 5.33 \mathrm{KCl} 0.441 \mathrm{KH}_{2} \mathrm{PO}_{4} 4.17 \mathrm{NaHCO}_{3} 110 \mathrm{NaCl} 0.338 \mathrm{Na}_{2} \mathrm{HPO}_{4} 27.5 \mathrm{CH}_{3} \mathrm{COONa}_{10} \mathrm{HEPES}$ and $\mathrm{pH}$ were adjusted to 7.2 by titration with $\mathrm{HCl}^{22}$. For the calibration of intracellular $\mathrm{pH}$ using SNARF, we used modified HBSS (in mM): $1.26 \mathrm{CaCl}_{2}, 0.493 \mathrm{MgCl}_{2}, 0.407 \mathrm{MgSO}_{4} 140 \mathrm{KCl} 0.441 \mathrm{KH}_{2} \mathrm{PO}_{4} 4.17 \mathrm{NaHCO}_{3} 0.338$ $\mathrm{Na}_{2} \mathrm{HPO}_{4} 10$ HEPES: with $10 \mu \mathrm{M}$ nigericin and $\mathrm{pH}$ was adjusted to 7.6, 7.4, 7.2, 7.0, 6.8, 6.6, 6.4, 6.2 with $\mathrm{NaOH}$ or $\mathrm{HCl}$. Regents were purchased from Nacalai tesque (Isoproterenol), Ajinomoto (Aspartame) and Wako Pure Chemical Industries (others). MCL was purified from pulps of the miracle fruits (Richadella dulcifica) as reported previously $^{29}$.

Intracellular pH imaging. HEK 293 cells were loaded with SNARF-5F-acetoxymethyl ester (Life Technologies Corporation) for $30 \mathrm{~min}$ at $37^{\circ} \mathrm{C}$. The same perfusion system in $\mathrm{Ca}^{2+}$ imaging was used to apply acid solutions. SNARF dye was excited with $488 \mathrm{~nm}$ laser in NIS elements (Nikon), and the ratio of fluorescence emissions at 640 and $580 \mathrm{~nm}$ (F640/F580) were captured every $5 \mathrm{~s}$ using a Nikon C2Si camera and Image Suite software (Nikon). Intracellular $\mathrm{pH}$ were measured by calibration curve obtained from modified HBSS at different $\mathrm{pH}^{30,31}$.

Data Analysis. In the analysis of single cell responses, changes in $\left[\mathrm{Ca}^{2+}\right]_{\mathrm{i}}$ were monitored as changes in fluo- 4 fluorescence. Fluorometric signals are expressed as relative fluorescence changes: $\Delta \mathrm{F} / \mathrm{F}_{0}=\left(\mathrm{F}-\mathrm{F}_{0}\right) / \mathrm{F}_{0}$, where $\mathrm{F}_{0}$ denotes the baseline fluorescence level. The magnitude of the calcium increases from 10 to $30 \mathrm{~s}$ after stimulus onset were measured and averaged. The data were expressed as the mean \pm S.E. of the $\Delta \mathrm{F} / \mathrm{F}_{0}$ value and used for statistical analysis. $\mathrm{EC}_{50}$ values were calculated from individual cumulative $\mathrm{pH}$-dependent-response data using curving-fitting routines of Origin 5.0 (Microcal Software). The effects of acid solution and mutation were analyzed by a two-way ANOVA and the post hoc Tukey-Kramer test. The effects of mutation on sweet responses were evaluated by multivariate ANOVA and the post-hoc Tukey-Kramer test. All calculations were performed using the statistical software package IBM SPSS Statistics (IBM).

\section{References}

1. Brouwer, J. N., van der Wel, H., Francke, A. \& Henning, G. J. Mieraculin, the sweetness-inducing protein from miracle fruit. Nature 220, 373-374 (1968).

2. Kurihara, K. \& Beidler, L. M. Mechanism of the action of taste-modifying protein. Nature 222, 1176-1179 (1969).

3. Brouwer, J. N. et al. The Sweetness-Inducing Effect of Miraculin - Behavioral and Neurophysiological Experiments in the RhesusMonkey Macaca-Mulatta. J. Physiol. 337, 221-240 (1983).

4. Hellekant, G., Ninomiya, Y. \& Danilova, V. Taste in chimpanzees. III: Labeled-line coding in sweet taste. Physiol. Behav. 65, 191-200 (1998).

5. Diamant, H., Hellekant, G. \& Zotterman, Y. The effect of miraculin on the taste buds of man, monkey and rat. Olfaction Tast. IV, ed Schneider, D. (Wissenschaftliche Verlagsgesellschaft MBH, Ger. pp 241-244 (1972).

6. Li, X. et al. High-resolution genetic mapping of the saccharin preference locus (Sac) and the putative sweet taste receptor (T1R1) gene (Gpr70) to mouse distal Chromosome 4. Mamm. Genome 12, 13-16 (2001).

7. Nelson, G. et al. Mammalian sweet taste receptors. Cell 106, 381-390 (2001).

8. Kunishima, N. et al. Structural basis of glutamate recognition by a dimeric metabotropic glutamate receptor. Nature 407, 971-977 (2000).

9. Koizumi, A. et al. Human sweet taste receptor mediates acid-induced sweetness of miraculin. Proc. Natl. Acad. Sci. 108, 16819-16824 (2011).

10. Ito, K. et al. Microbial production of sensory-active miraculin. Biochem. Biophys. Res. Commun. 360, 407-411 (2007).

11. Sanematsu, K. et al. Molecular mechanisms for sweet-suppressing effect of gymnemic acids. J. Biol. Chem. 289, 25711-25720 (2014).

12. Xu, H. et al. Different functional roles of T1R subunits in the heteromeric taste receptors. Proc. Natl. Acad. Sci. USA 101, 14258-14263 (2004).

13. Masuda, K. et al. Characterization of the modes of binding between human sweet taste receptor and low-molecular-weight sweet compounds. PLoS One 7, e35380 (2012).

14. Jiang, P. et al. Identification of the cyclamate interaction site within the transmembrane domain of the human sweet taste receptor subunit T1R3. J. Biol. Chem. 280, 34296-34305 (2005).

15. Nakajima, K. et al. Acid-induced sweetness of neoculin is ascribed to its pH-dependent agonistic-antagonistic interaction with human sweet taste receptor. FASEB J. 22, 2323-2330 (2008).

16. Nakajima, K. et al. Identification and Modulation of the Key Amino Acid Residue Responsible for the pH Sensitivity of Neoculin, a Taste-Modifying Protein. PLoS One 6, e19448 (2011).

17. DeSimone, J. A. \& Lyall, V. Taste receptors in the gastrointestinal tract III. Salty and sour taste: sensing of sodium and protons by the tongue. Am J Physiol Gastrointest Liver Physiol 291, G1005-10 (2006).

18. Lyall, V. et al. Decrease in rat taste receptor cell intracellular $\mathrm{pH}$ is the proximate stimulus in sour taste transduction. Am. J. Physiol. Cell Physiol. 281, C1005-C1013 (2001). 
19. Ganzevles, P. G. \& Kroeze, J. H. Effects of adaptation and cross-adaptation to common ions on sourness intensity. Physiol. Behav. 40, 641-646 (1987).

20. Ogiso, K., Shimizu, Y., Watanabe, K. \& Tonosaki, K. Possible involvement of undissociated acid molecules in the acid response of the chorda tympani nerve of the rat. J. Neurophysiol. 83, 2776-2779 (2000).

21. Arai, T., Ohkuri, T., Yasumatsu, K., Kaga, T. \& Ninomiya, Y. The role of transient receptor potential vanilloid-1 on neural responses to acids by the chorda tympani, glossopharyngeal and superior laryngeal nerves in mice. Neuroscience 165, 1476-1489 (2010).

22. Doi, T. et al. Extracellular $\mathrm{K}^{+}$and intracellular $\mathrm{pH}$ allosterically regulate renal Kir1.1 channels. J. Biol. Chem. 271, 17261-6 (1996).

23. Brouwer, J. N. et al. The sweetness-inducing effect of miraculin; behavioural and neurophysiological experiments in the rhesus monkey Macaca mulatta. J Physiol 337, 221-240 (1983).

24. Liu, B. et al. Molecular mechanism of species-dependent sweet taste toward artificial sweeteners. J. Neurosci. 31, 11070-11076 (2011).

25. Shigemura, N., Shirosaki, S., Sanematsu, K., Yoshida, R. \& Ninomiya, Y. Genetic and molecular basis of individual differences in human umami taste perception. PLoS One 4, e6717 (2009).

26. Max, M. et al. Tas1r3, encoding a new candidate taste receptor, is allelic to the sweet responsiveness locus Sac. Nat. Genet. 28, 58-63 (2001).

27. Li, X. et al. Human receptors for sweet and umami taste. Proc. Natl. Acad. Sci. USA 99, 4692-4696 (2002)

28. Horton, R. M., Hunt, H. D., Ho, S. N., Pullen, J. K. \& Pease, L. R. Engineering hybrid genes without the use of restriction enzymes: gene splicing by overlap extension. Gene 77, 61-68 (1989).

29. Theerasilp, S. et al. Complete amino acid sequence and structure characterization of the taste-modifying protein, miraculin. J. Biol. Chem. 264, 6655-6659 (1989).

30. Kreindler, J. L. et al. Interleukin-17A induces bicarbonate secretion in normal human bronchial epithelial cells. Am. J. Physiol. Lung Cell. Mol. Physiol. 296, L257-L266 (2009).

31. Lee, R. J., Harlow, J. M., Limberis, M. P., Wilson, J. M. \& Foskett, J. K. $\mathrm{HCO}_{3}{ }^{-}$secretion by murine nasal submucosal gland serous acinar cells during $\mathrm{Ca}^{2+}$-stimulated fluid secretion. J. Gen. Physiol. 132, 161-183 (2008).

\section{Acknowledgements}

We thank Drs. Gary Beauchamp and Joe Brand (Monell Chemical Senses Center) for their valuable suggestions on the manuscript. This work was supported in whole or part by KAKENHI Grants 23249081, 26670810, and 15H02571(to Y. N.) and 23792128, 25861759, and 15K11045 (to K. S.).

\section{Author Contributions}

Y.N. planned and supervised the project. K.S. and Y.N. designed the experiments. K.S., M.K. and N.S. performed the experiments. K.S. and M.K. analysed data. S.N. contributed new reagents/analytic tools. K.S., R.Y. and Y.N. wrote the paper.

\section{Additional Information}

Supplementary information accompanies this paper at http://www.nature.com/srep

Competing financial interests: The authors declare no competing financial interests.

How to cite this article: Sanematsu, K. et al. Intracellular acidification is required for full activation of the sweet taste receptor by miraculin. Sci. Rep. 6, 22807; doi: 10.1038/srep22807 (2016).

(c) (1) This work is licensed under a Creative Commons Attribution 4.0 International License. The images or other third party material in this article are included in the article's Creative Commons license, unless indicated otherwise in the credit line; if the material is not included under the Creative Commons license, users will need to obtain permission from the license holder to reproduce the material. To view a copy of this license, visit http://creativecommons.org/licenses/by/4.0/ 